\title{
Inter and Intra Observer Reproducibility of the New Oxford CCD Scheimpflug Camera
}

\author{
MARTIN L. HARRIS, GEORGE T. H. SMITH, NICHOLAS A. P. BROWN \\ Oxford
}

\begin{abstract}
Summary
Scheimpflug photography is a well recognised technique for obtaining sagittal views of the anterior structures of the human eye in vivo. A new generation of Scheimpflug camera, which uses a CCD (charge coupled device) instead of film, permitting the digitised image achieved to be directly analysed using computerised linear scanning densitometry, is described. The advantages and present limitations of this system over the older film using system are discussed and the reproducibility of the new CCD system in its ability to measure certain features of the crystalline lens is presented.
\end{abstract}

The technique of Scheimpflug photography has been shown to be of value in the study of the structures of the anterior segment of the eye. ${ }^{1,2.3 .+5}$ In order to apply this method to the investigation of cataract the sources of variability must be studied and quantified.

Film-based systems have several disadvantages when considering long term clinical trials. These are mostly based on the reproducibility of film development techniques and the question of storage over a period of years. Many of these disadvantages can be overcome by the use of CCD (charge coupled device) technology.

In this study we present the inter and intra observer reproducibility of the Oxford CCD Scheimpflug slit-image camera used in conjunction with the Oxford Modular Cataract Image Analysis System, ${ }^{+}$supplied by Marcher Enterprises Ltd.*

\section{Method}

The Oxford CCD Scheimpflug slit image cam- era is of the same basic design as that described by Brown in $1969,{ }^{6}$ with the film replaced by a CCD. The method of photography and image analysis was the same as that described by Sparrow. ${ }^{+}$The new CCD system controls for accurate fixation and alignment of the eye in the same way as the film using camera and also has an added feature that allows images only to be grabbed when the eye is in the correct position. This facility can be manually overridden when it is desireable to take off axis images.

The subjects were patients attending the Clinical Cataract Research Unit at the Oxford Eye Hospital. The patient selection was random and was not intended to be representative of any particular group. All the subjects were maximally dilated with Tropicamide $1 \%$ and Phenylepherine $10 \%$.

Interobserver variability of the photography was estimated by two different observers photographing twenty eyes of ten subject on the same day. Between photographs the sub-

${ }^{*}$ Marcher Enterprises Ltd, 6 Twyford Road, Rotherwas Industrial Estate, Hereford HR2 6JR, England.

From: The Clinical Cataract Research Unit, Nuffield Laboratory of Ophthalmology, Walton Street, Oxford OX2 6AW.

Correspondence to: Martin L. Harris FRCS, FCOphth, The Clinical Cataract Research Unit, The Nuffield Laboratory of Ophthalmology, Walton Street, Oxford OX2 6AW. 
jects were asked to sit back from the camera apparatus. The CCD gain setting was kept constant throughout. The analysis was performed by one of the observers several weeks after the photographs were taken. Seven features were measured for each photograph. These were: the central nuclear dip, the anterior cortical peak (C1), the deep cortical peak (C3), the anterior and posterior nuclear areas, the anterior chamber depth and the total lens width. The system can also estimate the lens radius of curvature which was not measured in the present study.

The anterior and posterior nuclear areas are planimetric measurements taken from an area of the densitogram tracing $1 \mathrm{~mm}$ in front of and $1 \mathrm{~mm}$ behind the central nuclear dip respectively.

The coefficients of variation and the $95 \%$ confidence intervals for the differences between measurements were calculated for each feature. ${ }^{7}$

Interobserver variability of the analysis was estimated by analysing 20 different photographs on two separate occasions by two different observers. The same seven features were measured and the coefficients of variation with the $95 \%$ confidence intervals for the differences were calculated.

Intraobserver variability of the photography and analysis combined was estimated by one observer photographing 20 eyes of 10 subjects on two occasions three weeks apart. The photographs were then analysed by that same observer.

In every case the analysis was performed in a blind manner so that the observer was una-

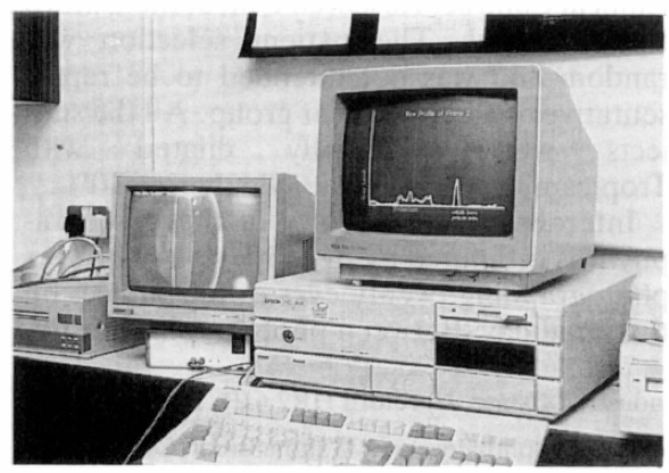

Fig. 1. The Oxford Modular Cataract Image Analysis System. ware of the result of any previously performed analysis.

Analysis was performed using a dedicated image analysis PC, the program being mouse driven.

The photograph is displayed on a video monitor whilst the computer screen shows the instruction screens and microdensitometry traces (see Fig 1).

Firstly, the photograph is standardised by reference to the two internal standard densities displayed in the upper right hand corner of the captured image. Once calibrated for neutral density, the computer prepares a micro-densitometry trace by averaging the values of a horizontal strip of 10 pixels through the centre of the image.

The seven parameters measured can be separated by type:

(1) Biometry; anterior chamber depth and total lens width

(2) Densitometry; measurement of peaks and the central nuclear dip. On the typical trace two anterior peaks are easily identifiable. The first peak represents the capsule and the subcapsular cortex ( $\mathrm{C} 1$ peak) and the second peak represents the deep anterior cortex (C3 peak) respectively (8).

(3) Planimetry; measurement of the area under the densitometry curve. The limits of each area being defined by the analyser using the mouse and the cursor visible over the video image. The anterior and posterior nuclear areas were measured in this way by defining the central nuclear dip and measuring the area under the curve for $1 \mathrm{~mm}$ either side of this.

Table I Inter observer variability of photography.

\begin{tabular}{|c|c|c|}
\hline Feature & $\begin{array}{l}\text { Coefficient } \\
\text { of variation }\end{array}$ & $\begin{array}{l}95 \% \text { Confidence } \\
\text { interval for } \\
\text { the difference } \\
\text { between two } \\
\text { measurements }\end{array}$ \\
\hline Central nuclear dip & $3.3 \%$ & 1.42 \\
\hline $\begin{array}{l}\text { Anterior capsule peak } \\
\text { (p1) }\end{array}$ & $4.0 \%$ & 1.67 \\
\hline $\mathrm{C} 3$ peak & $10.0 \%$ & 6.21 \\
\hline Anterior nuclear area & $3.7 \%$ & 49.56 \\
\hline Posterior nuclear area & $3.4 \%$ & 46.89 \\
\hline $\begin{array}{l}\text { Anterior chamber } \\
\text { depth }\end{array}$ & $1.0 \%$ & 0.08 \\
\hline Total lens width & $0.8 \%$ & 0.11 \\
\hline
\end{tabular}


Table II Inter observer variability of Analysis.

\begin{tabular}{|c|c|c|}
\hline Feature & $\begin{array}{l}\text { Coefficient } \\
\text { of variation }\end{array}$ & $\begin{array}{l}95 \% \text { Confidence } \\
\text { interval for } \\
\text { the difference } \\
\text { between two } \\
\text { measurements }\end{array}$ \\
\hline Central nuclear dip & $2.0 \%$ & 0.92 \\
\hline C1 peak & $4.5 \%$ & 2.28 \\
\hline $\mathrm{C} 3$ peak (p2) & $3.4 \%$ & 2.29 \\
\hline Anterior nuclear area & $2.9 \%$ & 43.04 \\
\hline Posterior nuclear area & $1.5 \%$ & 23.60 \\
\hline $\begin{array}{l}\text { Anterior chamber } \\
\text { depth }\end{array}$ & $1.6 \%$ & $\begin{array}{l}0.11 \\
0.16\end{array}$ \\
\hline Total lens width & $1.1 \%$ & 0.16 \\
\hline
\end{tabular}

\section{Repeatability Results}

The results of the interobserver variability of photography are shown in Table I, while those of the interobserver variability of analysis and those of intraobserver variability of photography and analysis combined are shown in Tables II and III respectively. The 95\% confidence intervals for the differences between the area measurements are greater because these measurements are much larger.

In general the results fall within acceptable limits of repeatability. ${ }^{5}$ Only the results for the C3 peak for both intra and inter observer variability for the photography were above $5 \%$.

\section{Discussion}

A charge coupled device consists of a matrix of discrete silicone imaging elements, called photosites, that have a voltage output proportional to the intensity of the incident light. ${ }^{9}$

Using a CCD camera, images are taken

Table III Intra observer variability of photography and analysis combined.

\begin{tabular}{|c|c|c|}
\hline Feature & $\begin{array}{l}\text { Coefficient } \\
\text { of variation }\end{array}$ & $\begin{array}{c}95 \% \text { Confidence } \\
\text { interval for } \\
\text { the difference } \\
\text { between two } \\
\text { measurements }\end{array}$ \\
\hline Central nuclear dip & $3.8 \%$ & 1.72 \\
\hline C1 peak & $4.3 \%$ & 5.38 \\
\hline C3 peak & $7.0 \%$ & 4.73 \\
\hline anterior nuclear area & $3.2 \%$ & 46.02 \\
\hline $\begin{array}{l}\text { posterior nuclear area } \\
\text { anterior chamber }\end{array}$ & $4.2 \%$ & 65.57 \\
\hline depth & $1.3 \%$ & 0.12 \\
\hline total lens width & $1.0 \%$ & 0.15 \\
\hline
\end{tabular}

quickly and efficiently and can be immediately viewed on a screen to check that they are satisfactory. The instantaneous digitisation allows for quick manipulation and analysis of the images and obviates the necessity for film development. Many images can be stored in digital form on optical media (more than 700 per disc), thus avoiding the deterioration that occurs with stored film and enabling the images to be presented in exactly the same position, for computerised analysis. The known linear response of the CCD, makes density measurements more accurate than film which has a sigmoid shaped response curve (see Figs $2 a$ and $2 b$ ).

Another important feature of the CCD is that once installed it does not require frequent replacement as does film. This not only saves time and money but also dispenses with problems such as the variability in film from different batches-an important consideration for long clinical trials.

In addition using a $\mathrm{CCD}$, live images can be transferred to a video tape allowing dynamic studies of, for example, accommodation.

In designing a CCD slit-image camera a compromise has to be reached between resolution and data handling plus storage. The CCD selected for the Marcher camera has a pixel array of 604 by 588 and the frame store handles 512 by 512 , which is considered to represent a reasonable compromise. The width of each pixel represents $30 \mu \mathrm{m}$ in the eye, which is the limiting factor to the resolution. In practice the resolution is satisfactory for most investigations on the lens, although

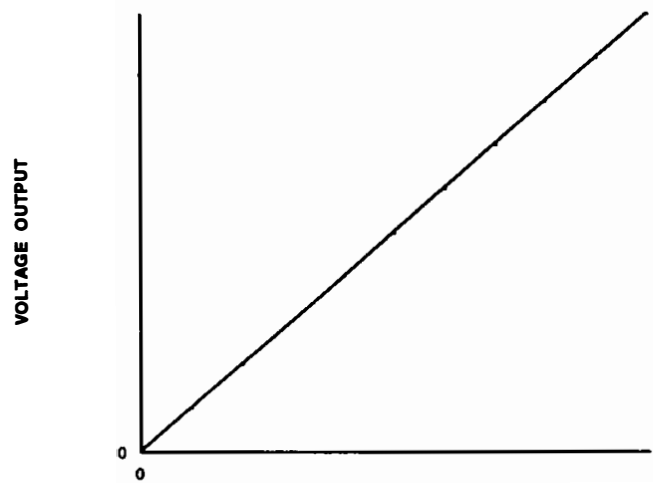

INTENSITY OF INCIDENT LIOHT

Fig. 2a. The linear response of the CCD. 


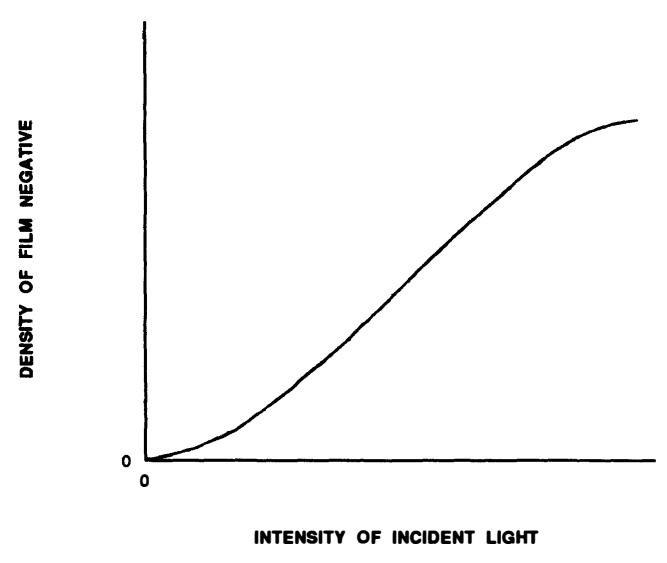

Fig. 2b. The sigmoid response of film.

the ability to resolve the detail of the capsule and of the anterior subcapsular clear zone is less than that of the older Brown² film using slit-image camera. This is partly because of the greater optical magnification of the film using camera at 1.75:1 (compared with 0.5:1 for the CCD), in which the geometric optics results in a more horizontally spread out image. It will be practical to increase the resolution of CCD images by making use of the advances in computer design and data storage, which will allow the use of CCDs that are both physically larger and have a larger pixel array.

With film it is possible to make colour photographs in order to analyse coloured features. This is not possible with the present $\mathrm{CCD}$, but colour analysis should be feasible with the use of a colour CCD.

The technique is most suited to measurements of density confined to the nucleus and to biometric measurements. This is in agreement with the work of Chylack et al. ${ }^{11}$ who also found slit-image photography to be more reliable for nuclear measurements.

We would recommend that for monitoring the progression of cataract, analysis of Scheimpflug slit images should be used in conjunction with the analysis of retroillumination images, since the latter may prove to provide more information for the progression of cortical opacities.

In our study, planimetry as compared to peak measurements for nuclear density came out well in terms of repeatability and may offer more information than a single peak measurement. This was not expected since a previous study by Hockwin et al. showed that planimetry was less repeatable than peak measurements. "In our study, however, planimetry was confined to the central nucleus whereas Hockwin extended his measurements to the whole lens.

In general, we believe that the introduction of CCD technology has brought about a considerable advancement in the field of lens opacity quantification. There is room for improvement, however, and in the years to come we should see the development of systems with superior resolution.

Key words: Charge Coupled Device, Reproducibility, Scheimpflug Photography.

\section{References}

${ }^{1}$ Niesel Von P. Spaltlampenphotographie mit der Haag-Streit Spaltlampe 900. Ophthalmologica (Basel) 1966, 151, 489.

'Brown NAP. Quatitative slit image photography of the lens. Trans Ophthalmol Soc UK 1972, 92: 303-17.

'Smith GTH, Brown NAP, Shun-Shin GA. Light scatter from the central human cornea. Eye 1990, 4: $584-8$.

${ }^{+}$Sparrow JM, Brown NAP, Shun-Shin GA, Bron AJ. The Oxford Modular Cataract Image Analysis System. Eye 1990, 4: 638-48.

"Hockwin O, Dragomirescu V, Laser H. Measurement of lens transparency and its disturbance by densitometric image analysis of Scheimpllug photographs. Graefes Arch Clin Exp Ophthalmol 1982, 219: 255-62.

"Brown NAP. Slit image photography. Trans Ophthalmol Soc UK 1969, 89: 387-408.

Bland M. An Introduction to Medical Statistics. Oxford. Oxford University Press. 1989: 276-278.

s Sparrow JM. Bron AJ. Brown NAP, Ayliffe W, Hill AR. The Oxford Clinical Cataract Classification and Grading System. Int Ophthalmol 1986, 9: 207-25.

"Gonzalez RC and Wintz P. Digital Image Processing. Second Edition. Addison-Wesley Publishing Company. 1987: 9.

"Chen SY, Chylack LT, White D. Topcon SL-45 photography a suitable technique for documenting nuclear but not cortical cataractous changes in vivo. Invest Ophthalmol Vis Sci 1985, 26, 3: 119 (Suppl).

${ }^{11}$ Hockwin O, Laser H, Kapper K. Image Analysis of Scheimpflug Negatives. Comparative Quantitative Assessment of the Film Blackening by Area Planimetry and Height Measurements of Linear Densitograms. Ophthalmic Res 1988, 20: 99-105. 